\title{
Representation of "I-Stranger" Interaction as a Communication Risks Predictor
}

\author{
Elena V. Ryaguzova \\ Department of Psychology, Saratov State University, Saratov, Russia \\ Email: rjaguzova@yandex.ru
}

Received February 2014

\begin{abstract}
The paper contains a theoretical study of the personal representation of "I-Stranger" interaction. The differentiation of the native-strange and close/ours-alien dichotomies is suggested. The empirical study $(\mathrm{N}=100)$ which highlighted the ambivalent nature of personal representation of "I-Stranger" interaction, its ambiguity and variability has been conducted. The prospects of representation of "I-Stranger" interaction studying in modern multicultural world are stated. The applied aspect of the stated problem can be implemented in the training programs on the personality intercultural sensitivity development.
\end{abstract}

\section{Keywords}

Social Psychology, Personality, Communication Risks, Representation “I-Stranger”, Dichotomy "We-They", Ambivalence of the "Stranger" Representation

\section{Introduction}

Modern society is described with a variety of metaphors characterizing its different perspectives figuratively and clearly and providing a kind of categorical shift from the content of the offered metaphor to its clearly articulated meaning: "the play society”/“La societé du spectacle” (Guy Debord), "the consumer society”/“La société de consummation" (Jean Baudrillard), "the knowledge society" (R. Lane), "the information and post-industrial society" (Alvin Toffler), "the network society" (Manuel Castells), "the global village” (Marshall McLuhan), "the individualized society" (Zygmunt Bauman), "the risk society” (Ulrich Beck). The variety of metaphors reflects the actual ongoing social processes and indicates the availability of such invariant features of the modern society as globalization, high-volume production and consumerism, information and visual culture, virtualization and demonstration/manifestation of different risks.

The risks of the modern society are in the focus of our research interest. The psychological discourse of the notion "risk" is shown clearly in the following contexts: 1) risk as an expectation measure for success/failure defined by the failure probability ratio and value of negative consequences; 2) risk as an action associated with loss and failure; 3) risk as situation of alternative choice between safe but less appealing actions and more beneficial but dangerous solutions; 4) risk as a value described by the binary oppositions "good-evil", "acceptableforbidden", "fair-unfair"; 5) risk as responsibility concerning regulation and psychological obligations to be accountable for actions and their consequences. 
The purpose of this paper is to analyze of the personal representation of "I-Stranger" interaction, and search its content and role/importance in the psychological risks genesis.

\section{Psychological and Communication Risks}

In the framework of this article we terminate the area of psychological risks with communication risks, deterministic processes of interaction and communication, interpersonal relations, personal experiences and evaluations. Communication risks in the course of I-Other interaction are associated with the loss or minimization of contacts, developing of intercourse barriers, overrunning the roles, uncertainty and complexity of dynamic features of the situation forecasting. Risks can be due to both communicators' personalities, their communication competence level, and set social and psychological attitudes, socially developed expectations and stereotypes. Communication success and efficiency depend on to what extent the ability of the interaction participants to see in "Other" an equal partner and simultaneously acknowledge their right to be different is developed. Moreover, concerning communication risks we intentionally specialize the subject area of our study limiting it to the contacts with "Other" like "Stranger".

\subsection{Analysis of the Construct "Stranger" and Notion "Strange"}

The construct "Stranger” suggests the out-group existence which actualizes the Subject's anxieties, fears, or aggressive attitudes and opposed/hostile settings. Some of these groups are easily differ in group affiliation formal matters, and others are categorized with casual or least significant differences. It is important that the less evident these differences are, the more rigorous criteria of the group differentiation are necessary to make these differences more prominent and noticeable.

The essential for our analysis fact should be mentioned-the logical connotation of the notion "Strange" in many cultures there are such characteristics as dangerous, evil, hostile. "Strange" is positioned as a dual pair to "one's own", typified through the reference to the social category "We" and evaluated/assessed as dangerous, hostile, risky. Opposition "We-They" is mainly based on stereotypes—social attitudes formed and adopted in the course of socialization and acculturation. These are stereotypes which enable to recognize "ours” and "strange” by few decisive criteria, save time and personal resources, emphasize and clarify significant differences between groups as well as comment on the behavior towards other groups which is often beyond ethical standards working with the regard to "ours". Such approach is traditional for psychology but from our point of view it too extends meaningful and semantic field/area of the construct "Strange", preventing from making clear the conceptual framework of finer-grained distinctions. It points up the danger of "Strange", eliminating the fact that in certain situation "ours” can be the source of danger and "strange” appears to act as a resource of development.

\subsection{The Determination of the Notions}

To develop more flexible scheme for differentiation we suggest to draw a distinction between the notions "Strange” and “Alien”, taking binary pairs “ natural-strange”, “close/ours-alien” as a basis, put forward by V.I. Slobodchikov [1]. Opposition "natural-strange” reflects blood relation, belonging to a particular clan, specifity of the relations and involvement into the specific group. "Natural” is described through the personal attitudes/ relations-parental, matrimonial—when the personality can ontologize themselves, i.e. to develop their being with Others and for Others, associate/refer themselves with/to the world, gain the qualitative determinancy in it and hold one's own position, i.e. to make a self-determined personality [2]. "Strange” may not be labeled as dangerous and threatening but arouse either indifference or interest and curiosity, fixing identity based on differences compared to those who this personality appears not to be. In this context the meaning interpretation of the "strange" depends on the situational context, the intercommunication purpose, territorial localization, status of the "Strange", their command/holding of economical, cultural and social capitals, the rate of threatening to the in-group and factors/indexes setting different parameters to social distance.

Opposition “close/ours_alien” represents spiritual affinity/closeness, similarity of interests, attitudes, shared meanings, and common invariant values on one of its poles. In this case the example of co-relations is friendly, intimate relationship based on affection and attraction. There are contrary qualities and characteristics on the pole “Alien".

The main differentiating principles of distinction between "insiders/us" and "outsiders/them” are the prin- 
ciples of social comparison and inequality, expecting aprioristic dominance of an in-group. In the extreme variant "Strange" and "Alien" are transformed into the image/figure of the "Enemy" represented by the particular people, visualizing the whole scale of negative qualities and characteristics, disembodied and impersonal mass, peaceful co-existence with whom is impossible and morally depraved/ill-natured; abstract entity constituting real, potential or virtual danger to the group existence.

\section{Organization and Research Methods}

The study involved 100 men aged 18 - 20 years. The study process included three empirical series. In the first series values ranking was sequentially conducted according to the varied optics of Self-conception and virtual Stranger visions to determine values arrays configuration personality-centered and attributed to Strange by the personality (methods of Milton Rokeach); the second series was aimed at identifying emotional-evaluative content of representations "I", "Ideal”, "Strange" (the modified version of G.U. Soldatova's method [3]); during the third series the transformation of the emotional-evaluative component of the stereotyped image of "Strange" as compared with the representation of "Enemy" was studied (G.U. Soldatova's method).

\section{Study Deliverables, Analysis and Discussion}

The results of the first series of studies have revealed the differences in the values configuration attributed by the personality to them and to Strange. However, these value sets are not opposing one another or mutually exclusive, in fact they have intersecting areas. Thus, for the majority of the test groups health, love, active life were the most significant values, but entertainment, nature and art beauty were the least valuable. As for the value sets attributed to Stranger we can distinguish their quantitative and qualitative characteristics. We refer a greater range of respondents opinions to the quantitative features due to the uncertainty of the character of Stranger, and different values configuration where development, self-confidence, easy circulation life were priority-oriented, and the happiness of others and nature and art beauty were the least valuable, to the qualitative features. Consequently, the configuration of values attributed by the personality to them and to Stranger lack of the expressed inversion, have intersecting points and vary rather in such psychological culture measurement as "collectivism-individualism" [4].

The results of the second and third series were obtained using a modified version of the G.U. Soldatova's questionnaire and are presented in "Table 1".

Represented data testify that in subjective evaluation of oneself, one's own ideal and uncertain Stranger a non-personified figure of Stranger being a stereotyped image is characterized by high rates of ambivalence which indicates of fuzziness and uncertainty of the image evaluated/assessed, negative orientation and negative valence (as compared to I and Ideal). It should be noted that I-image is also ambivalent, furthermore, there are no significant differences between I-image and Stranger-image in the parameter "ambivalence.” From our point of view, the uncertainty of the Stranger-image is due to the fact that it is difficult to fill it meaningfully because it is not complementary to the I-image: there is no shared past, currently important present and anticipated future, there are no meeting points of existential meanings. If the construct "Enemy" is input into the comparative range (the results of the 3 series), then the reinforcement of the ambivalent characteristics of the Stranger -image takes place and transformation of the negative valence into positive is visible (at the level of the lowest values). In this case, "Stranger" stereotype appears to be subjectively more neutral image, not loaded with strongly marked connotative characteristics such as mobile, flexible, changeable representation, which is easy filling externally and is likely to be a modifier of behavioral pattern, values, meanings, attitudes and become a risks communication predictor.

Table 1. Emotional-evaluative component of the stereotyped images.

\begin{tabular}{|c|c|c|c|c|c|c|c|}
\hline & \multicolumn{3}{|c|}{2 series } & \multicolumn{4}{|c|}{3 series } \\
\hline & \multicolumn{7}{|c|}{ Evaluated constructs } \\
\hline & I & Ideal & Stranger & I & Ideal & Stranger & Enemy \\
\hline Ambivalence & 0.62 & 0.37 & 0.7 & 0.68 & 0.56 & 0.81 & 0.64 \\
\hline Extent & 0.32 & 0.56 & -0.26 & 0.3 & 0.46 & 0.06 & -0.3 \\
\hline Emotional orientation & 0.07 & 0.13 & -0.05 & 0.06 & 0.1 & 0.01 & -0.06 \\
\hline
\end{tabular}




\section{Conclusions}

The conducted theoretical study made it possible to differentiate the constructs "Strange” and "Alien”, and empiric study results confirmed the multiplicity and variability of personal representation of "I-Stranger" interaction. Construct "Stranger" lacks its own qualitatively-quantitative certainty and is easily filled with meaning content with account of personal or situational contexts.

In modern global multi-polar and flexible world a special consideration should be given to the "Stranger" stereotype. By the substantive content of this construct in particular it is necessary to modify the nature of interactions between large groups (e.g. ethnic, religious) and societies, generally, changing the known dichotomy "We-They", based on direct opposition and inevitable conflict between them for dual symmetrical pair "We-You". Relations within this dyad are also associated with self-determination, which is a key condition for inclusion into social relations net (work) and interactions, but herein a priori equality of parties/participants, respect to each other, differences recognition and tolerance for them are expected, that in whole causes the possibility of polylogical and polyphonic communications, reduces the communication risks and encourages the problem solving of social interactions harmonization.

\section{References}

[1] Slobodchikov, V.I. (2010) Co-existential Educational Community-A Source of Development and a Subject of Education. Newsworhiness in Educational Work and Teaching Activities, Edited by N.B. Krilova and M.U. Zhilina. Issue 1 (43). Слободчиков В.И. (2010) Со-бытийная образовательная общность-источник развития и субъект образования. Событийность в образовательной и педагогической деятельности. Под ред. Н.Б.Крыловой, М.Ю.Жилиной. вып. 1 (43).

[2] Starovoitenko, E.B. (2009) Vital Personality Relations Models in the Context of S.L. Rubinstein's Otno-Psychology. Philosophy of Russia of the Second Half of the Twentieth Century: S.L. Rubinstein, Edited by Abulkhanova, K.A., Moscow: ROSSPEN, 346-379. Старовойтенко Е.Б. (2009) Модели жизненных отношений личности в контексте отно-психологии С.Л. Рубинштейна. Философия России второй половины XX века: С.Л. Рубинштейн. (Под ред. К.А. Абульхановой). Москва: РОССПЭН. С. 346-379.

[3] Psychodiagnostics of the Personality Tolerance (2008) Edited by Soldatova, G.U. and Shaigerova, L.A., 66-71. Психодиагностика толерантности личности (2008) Под ред Солдатовой Г.У., Шайгеровой Л.А. С. 66-71.

[4] Triandis, G.R. (2011) Culture and Social Behavior, Moscow: Forum, 284. Триандис Г.К. (2011) Культура и социальное поведение. М.: Форум. 384c. 